УДК 338.242.2

http://doi.org/10.36906/KSP-2020/25

Карамов Д.Ф., Туфетулов А.М.

Казанский государственный энергетический университет 2. Казань, Россия

\title{
СИСТЕМЫ И МЕТОДЫ АНАЛИЗА ФИНАНСОВОЙ УСТОЙЧИВОСТИ ПРЕДПРИЯТИЯ
}

Аннотация. Обеспечение финансовой устойчивости любой организации является важнейшей задачей ее менеджмента. Финансовое состояние организации можно признать устойчивым, если при неблагоприятных изменениях внешней среды она сохраняет способность нормально функционировать, своевременно и полностью выполнять свои обязательства по расчетам с персоналом, поставщиками, банками, по платежам в бюджет и внебюджетные фонды и при этом выполнять свои текущие планы и стратегические программы. В статье рассмотрены системы и методы анализа финансовой устойчивости предприятия.

Ключевые слова: финансовая устойчивость; факторный анализ; коэффициенты финансовой устойчивости; вертикальный и горизонтальный анализ; интегральный анализ; сравнительный анализ.

Проанализировав мнения многих российских ученых, можно сделать вывод о том, что под финансовым состоянием понимается способность предприятия финансировать свою деятельность, как на данный момент времени, так и в обозримом будущем, максимально эффективно используя доступные финансовые ресурсы и капитал, при этом сохраняя финансовую конкурентоспособность и своевременно выполняя свои обязательства. Из определения финансового состояния видно, что анализ финансовой устойчивости играет в нем одну из главнейших ролей [4, с. 157].

Условием и гарантией выживания и развития любого предприятия является его финансовая устойчивость, так как если предприятие финансово устойчиво, то оно сможет справиться с неожиданным изменением конъюнктуры рынка, не оказавшись при этом на краю банкротства.

Чем выше его стабильность, тем больше преимуществ перед другими предприятиями, функционирующими в той же сфере, в получении кредитов и привлечении инвестиций. Финансово устойчивое предприятие способно своевременно рассчитываться по своим обязательствам с государством, внебюджетными фондами, работниками, контрагентами, что способствует укреплению его имиджа, а это главная составляющая нематериальных активов любой организации. 
Под финансовой устойчивостью понимается такое положение финансовых ресурсов, при котором гарантируется наличие достаточной доли собственных средств, стабильная доходность, а также стабильное обеспечение производства.

Рассмотрение финансовой устойчивости является неотьемлемой частью оценки финансового состояния и, несомненно, оказывает влияние на итог анализа финансового состояния предприятия.

Анализ финансовой устойчивости преследует следующие цели: определение уровня благосостояния организации в настоящий момент времени, выявление факторов, оказывающих влияние на финансовое состояние, определение недостатков в работе и причин их возникновения, а также прогноз и рекомендации по оптимизации деятельности, ориентированные на ближайшее будущее компании.

Анализ финансовой устойчивости предприятия проводит как само предприятие, так и внешние представители: банки, оценивающие степень риска при кредитовании данного предприятия; поставщики для своевременного получения платежей; налоговые органы, выполняющие план по поступлению денежных средств в бюджет, и т. д. Согласно этому выделяют внутренний и внешний анализ [6, с. 3].

Внутренний анализ осуществляется непосредственно на предприятии, его собственными специалистами. Результаты такого анализа используются для планирования, прогнозирования и контроля финансового состояния организации.

Внутренний анализ обладает преимуществом перед внешним, так как оценщик обладает большим объемом информации, используя данные внутреннего управленческого учета, что позволяет с большей точностью спрогнозировать финансовое состояние предприятия, а также оценить его экономический потенциал [2, с. 167].

Внешний анализ осуществляется инвесторами, контрагентами и органами контроля на основе публичной годовой (или квартальной) отчетности. Недостатком данного анализа является ограниченность доступной информации и использование типовых методик, по которым можно рассчитать лишь ограниченное число показателей.

Типичный алгоритм анализа финансовой устойчивости включает следующие этапы: сбор необходимого объема информации; оценка достоверности информации, проверка данной информации (например, с использованием независимого аудита); обработка информации, составление аналитических таблиц и агрегированных форм отчетности; расчет и анализ финансовых показателей; заключение об устойчивости финансового состояния организации.

Среди множества классификаций методов анализа финансовой устойчивости можно выделить неформализованные методы, основанные на описании аналитических процедур: это методы сценариев, сравнения, экспертных оценок, и формализованные, такие как метод цепных подстановок, группировки, средних и относительных величин, дисконтирования, интегральный и другие. В неформализованных методах присутствует некий субъективизм, основаны они на опыте тех, кто их применяет. Формализованные методы более строги, используют четкий логический аппарат и выявляют аналитические закономерности.

По направлению анализа выделяют: ретроспективный и перспективный. Ретроспективный анализ является анализом прошлой финансовой информации, а перспективный анализ, соответственно, является прогнозным на будущее [1, с. 4]. 
По детализаџии выделяют экспресс-анализ, который проводится по основным финансовым показателям и в основном характерен для внешнего анализа, и детализированный финансовый анализ, проводящийся по всем показателям и дающий полную характеристику организации.

Различают также различные подходы к оценке финансовой устойчивости: ресурсный, традиционный, ресурсно-управленческий, основанный на теории нечетких множеств и т. д.

Традиционный подход оценки финансовой устойчивости основывается на расчете таких коэффициентов, как коэффициент задолженности по кредитам банков и займам; коэффициент задолженности другим организациям; коэффициент задолженности фискальной системе; коэффициент внутреннего долга; степень платежеспособности по текущим обязательствам; коэффициент покрытия текущих обязательств оборотными активами; собственный капитал в обороте; доля собственного капитала в оборотных средствах; коэффициент автономии.

В ресурсном подходе различают различные виды ресурсов (финансовые, интеллектуальные, материальные), в разрезе получения результата от них. Определяют состав ресурсов, динамику их движения, эффективность использования.

В ресурсно-управленческом подходе основополагающим является качество управления ресурсами (организация финансового менеджмента), при этом оцениваются темпы роста управленческих расходов в соотношении с полученным результатом.

В стохастическом анализе возможно спрогнозировать вероятность потери финансовой устойчивости, банкротства предприятия; в теории нечетких множеств - по отдельным показателям оценить вероятность банкротства. Выделить границы нечетких подмножеств, в соответствии с которыми определить стадию кризиса предприятия (нормальная устойчивость, неустойчивое положение, кризисное положение и т. д.) [3, с. 189].

Среди систем и методов анализа финансовой устойчивости можно выделить следующие виды анализа, отраженные на рисунке:

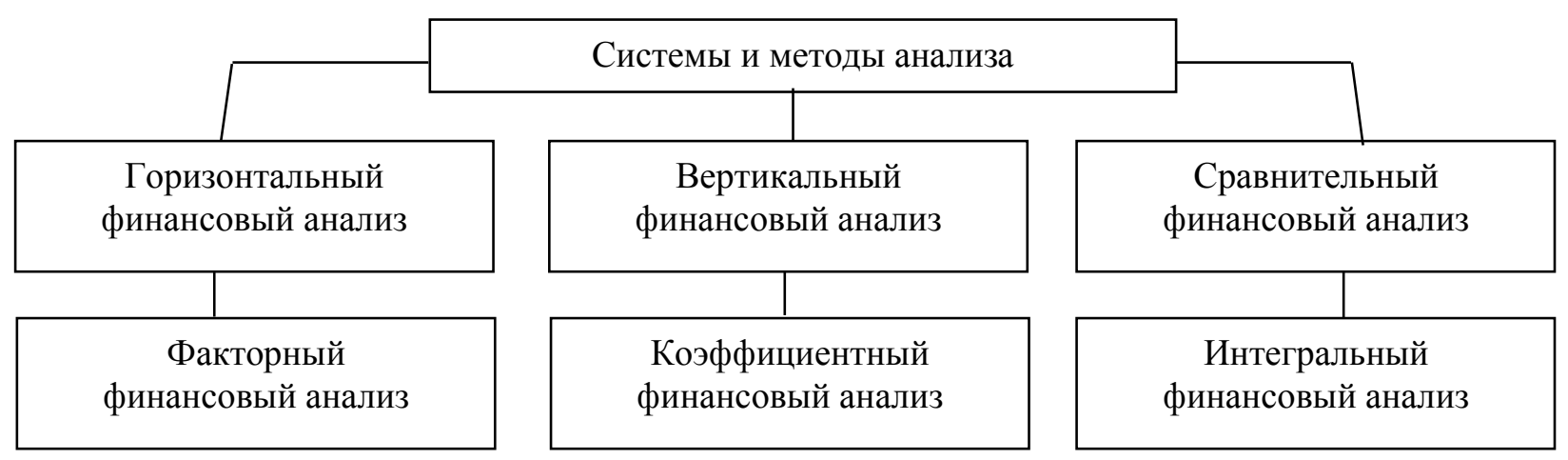

Рис. Системы и методы анализа финансовой устойчивости предприятия

Итак, можно выделить [5, с. 207]:

- горизонтальный финансовый анализ - предполагает анализ финансовых показателей во времени, для определения тенденций в динамике развития предприятия. Этот анализ основан на сравнении всех статей баланса или отчета о финансовых результатах с базисным годом, в результате чего появляется возможность определения темпов прироста по различным статьям отчетности; 
- вертикальный финансовый анализ - проводится исходя из структурного разложения показателей финансовой отчетности. Позволяет получить представление о структуре важнейших итоговых сумм финансовой отчетности, выявляя удельный вес отдельных статей отчетности в общем итоговом показателе (выявляет влияние каждой статьи на итоговый результат);

- сравнительный финансовый анализ - характеризует соотношение финансовых показателей данного предприятия с аналогичными показателями других предприятий и конкурентов, функционирующих в той же отрасли;

- факторный финансовый анализ - оценивает влияние отдельных факторов на итоговые финансовые показатели. Данный метод используется, как правило, при проведении внутреннего финансового анализа;

- метод финансовых коэффициентов - является ведущим методом анализа финансового состояния. Финансовые коэффициенты представляют собой отношение одного значимого показателя отчетности к другому, взаимосвязанному с ним. Коэффициентный метод позволяет проводить сравнительный анализ эффективности: с предшествующими годами или с заранее запланированными показателями;

- интегральный финансовый анализ - позволяет получить многофакторную углубленную оценку условий формирования отдельных агрегированных финансовых показателей.

Изучив современную литературу по анализу финансовой устойчивости, можно сделать вывод, что методик анализа много, они дополняют друг друга и позволяют более объективно оценивать финансовое состояние.

В зависимости от того, какие цели преследуются оценщиком, он обращает свое внимание на тот или иной соответствующий метод финансового анализа. Например, для кредиторов данной организации наиболее значимыми являются показатели ликвидности оцениваемой компании, для акционеров такими будут являться показатели рентабельности, для профсоюзов - расходы на оплату труда, объем и эффективность капитальных затрат, для ФНС - правильность начисления и уплаты налогов, страховых отчислений и т. д. Для оценки финансовой устойчивости предприятия необходимо для начала рассмотреть его имущественное положение. В ходе имущественного анализа изучаются изменения в объеме, составе и структуре имущества компании, а также динамика этих изменений. При оценке используют горизонтальный, вертикальный и коэффициентный анализ.

Итак, в отечественной и мировой практике используется ряд подходов к анализу финансовой устойчивости предприятия, методики можно разделить на типовые (с использованием приемов анализа типовых финансово-хозяйственных процессов) и частные (отраслевые, с задействованием каких-то определенных финансово-хозяйственных процессов).

Существующие методики подразделяются на методики, основанные на системе коэффициентов, интегральных показателей, системе неравенств и многомерных статистических методов и ЭММ [3, с. 192].

Методом анализа финансовой устойчивости является совокупность применяемых методов обработки экономической информации, которые ориентированы на решение аналитических задач и применяют показатели, характеризующие финансовую устойчивость 
предприятия, оценивают влияние внешних и внутренних факторов на совокупный показатель финансовой устойчивости предприятия [1, с. 4].

Наиболее актуальными методами оценки финансовой устойчивости предприятия, по оценкам исследователей, являются методы оценки чистых активов, коэффициентный метод, анализ динамики и структуры активов и пассивов, методы оценки обеспеченности собственными средствами.

На основе коэффициентного метода можно определить уровень платежеспособности предприятия, преимуществом его является относительная простота использования, открытость информации, необходимой для анализа. Это объясняет его популярность в изучении финансовой устойчивости. Недостатками метода являются при этом: неопределенность в терминологии (названиях коэффициентов), различия в формулах расчета коэффициентов, предлагаемых разными исследователями, и соответствующая разность в интерпретации одних и тех же коэффициентов. Различия имеются также и в предлагаемых нормативах допустимости коэффициентов [1, с. 24].

В коэффициентном методе различают два направления - расчет значений, которые характеризуют структуру капитала (первое направление), и значений, которые определяют уровень покрытия обязательств (второе направление). В рамках первого направления производят расчет коэффициентов финансовой независимости (левериджа), коэффициента финансовой устойчивости, обеспеченности активов оборотными средствами. В рамках второго направления: расчет коэффициентов покрытия процентов, денежного покрытия, полного покрытия затрат на обслуживание долга и т. д. [5, с. 212].

Различают типы финансовой устойчивости: абсолютная, нормальная, неустойчивое состояние предприятия и кризисное состояние. Каждое из состояний характеризуется набором тех или иных финансовых показателей предприятия.

\section{Литература}

1. Ельфимовская М.М. Особенности классификации финансовой устойчивости организации // Аллея науки. 2018. № 11(27). С. 4.

2. Красникова Н.В. Теоретические аспекты анализа финансовой устойчивости организации // Концепт. 2019. С. 167-169.

3. Кутин М.В. Сущность, цели и задачи определения уровня финансовой устойчивости предприятия // Вестник современных исследований. 2019. № 1.10. С. 189-192.

4. Марченкова И.Н. Финансовое состояние предприятия и пути его улучшения // Теория науки. 2020. № 3. С. 157-158.

5. Сафронова Ю.И. Анализ финансового состояния организации в современных условиях // Синергия наук. 2017. № 14. С. 207-212.

6. Сивак Е.И. Финансовая устойчивость компаний в современных условиях: проблемы и решения // Синергия наук. 2018. № 8. С. 3.

(СКарамов Д.Ф., Туфетулов А.М. 